\title{
TEACHING STRESS MANAGEMENT
}

The article titled Dentist Suicides ${ }^{1}$ is highly thought provoking and we thank Paul Hood's widow for allowing it to be published. As dental education in primary care outreach settings becomes increasingly common, clinical training is often framed by a live PDS+ NHS contract dealing with UDAs and KPIs. ${ }^{2}$

Final year dental students are already having to cope with the stress of the National Assessment for Foundation Training and the possibility of a low national ranking (and consequently no Foundation Training place available), all their various online computer assessments and those hurdles which others will only too readily remember of Finals case presentations, OSCEs and traditional written and viva examinations. One of our roles as educators is to ease the transition into Foundation training, handing over these exceptionally personable, bright and talented young professionals to vocational trainers. In support of this, we give our student colleagues (dental, hygiene/therapy and dental nursing) formal sessions on stress awareness and management.

There is an interesting contrast with the editorial in the same issue ${ }^{3}$ focusing on the profession taking a more holistic approach to our patients' health and wellbeing and being an integrated part of the healthcare team. However, if additional screening, such as blood pressure checks, are to be an extra burden to already over stretched dentists, realistic funding has to be put in place to provide for the additional members of the dental teams to achieve these important diagnostic and preventive general health measures.

Privately, we do worry about the environment in which our young colleagues will have to work and how they will cope with all the competing pressures of modern dental practice.

David R Radford, J Martin Colley, Paul Hellyer Portsmouth

${ }^{1}$ Renshaw J. Dentist suicides. Br Dent J 2013; 215: 593-594.

${ }^{2}$ Radford D R. A personal perspective: breaking new ground in Portsmouth in the integrated dental education and professional care. Higher Education Research Network Journal 2011;2: 67-71.

${ }^{3}$ Hancocks S. The hole and the whole. (editorial) Br Dent J 2013; 215: 541. 